[Contribution from the Chemical Laboratory OF the University of TeXas.]

\title{
A NEW SYNTHESIS OF IMINOACETONITRILE AND ITS CON- VERSION TO HYDRAZINODIACETIC ACID.
}

BY J. R. BAILEY AND D. F. SNYDER.

Received February $8,1915$.

Introduction.

From the work of various investigators ${ }^{1}$ it appeared highly probable that methyleneaminoacetonitrile, $\mathrm{CH}_{2}=\mathrm{NCH}_{2} \mathrm{CN}$, ${ }^{2}$ would readily add on prussic acid, and thus furnish an excellent method for the preparation of iminoacetonitrile, $\mathrm{NH}\left(\mathrm{CH}_{2} \mathrm{CN}\right)_{2}{ }^{3}$ Our first experiment in this direction showed that the expected reaction proceeds normally at room temperature, when the above methyleneamino compound is subjected to the action of either absolute or an aqueous prussic acid. This method of preparing the nitrile of iminodiacetic acid, on account of the ease with which the starting substances can be obtained, and, because of the fact that the reaction proceeds quantitatively without the formation of other products, may supplement the method of Eschweiler, referred to above, where, in the treatment of hexamethylenetetramine with prussic acid under different conditions, aminoacetonitrile, iminoacetonitrile, and nitrilotriacetonitrile, $\mathrm{N}\left(\mathrm{CH}_{2} \mathrm{CN}\right)_{3}$, are formed in varying amounts. Strangely enough, $\mathrm{M}$. Delepine states that methyleneaminoacetonitrile is indifferent to prussic acid. ${ }^{4}$ This investigator showed that ethylidene- $\alpha$-propionitrile, $\mathrm{CH}_{3} \mathrm{CH}=$ $\mathrm{NCH}\left(\mathrm{CH}_{3}\right) \mathrm{CN}$, and numerous alkylidene amines add on prussic acid; but, after trying under modified conditions to effect the reaction that, according to our observation proceeds so smoothly between methyleneaminoacetonitrile and prussic acid, he reported as follows: "J'ai constaté que ce corps $\left(\mathrm{CH}_{2}=\mathrm{NCH}_{2} \mathrm{CN}\right)$ restait absolument inaltéré sous l'influence de l'acide cyanhydrique à froid, en présence ou en l'absence de solvants." Delépine advances the supposed resistance of methyleneaminoacetonitrile towards prussic acid in support of the dimeric formula proposed by Klages for this substance. ${ }^{5}$ In case Klages' view of the molecular weight of methyleneaminoacetonitrile be correct, and we have no reason to doubt the correctness of his conclusion in this matter, we must ascribe to the prussic acid in the above reaction a depolymerizing action which probably precedes the additive action. A molecular weight determination showed conclusively that iminoacetonitrile is monomolecular. Granting that methyleneaminoacetonitrile is dimolecular, no insight into the constitution of the molecule is afforded by its chemical behavior be-

${ }^{1}$ Ber., 25, 2020 (I 892 ); Ann., 283, I I (1894); 290, I (I 896); 303, 75 (1898).

2 Ber., 27, 59 (1 894$)$.

'Ann., 278, 229 (1894).

- Bull. soc. chim, 29, 1202 (1903).

I. prakt. Chem., [2] 65, 192 (1902). 
cause depolymerization always accompanies its chemical changes. Frequently the group $\mathrm{N}=\mathrm{C}$ in polymerized molecules takes up $\mathrm{HCN}$ with the resultant addition product monomolecular, as in the above case investigated by us. Von Miller with his co-workers ${ }^{1}$ found that anhydroformaldehyde aniline, although trimolecular, and dimeric anhydrovaleraldehyde aniline showed the behavior toward prussic acid of simple monomolecular compounds, yielding anilidoacetonitrile and anilidovaleronitrile, respectively. Ethylideneaniline, on the other hand, proved indifferent to prussic acid. Furthermore, unpublished experiments conducted in this laboratory show that the complex insoluble reaction product of formaldehyde with hydrazine is not in any way altered by prussic acid. ${ }^{2}$ Delépine observed that the polymeric condition of alkylidene amines at lower temperatures is not always of moment in their behavior toward $\mathrm{HCN}$, as he found that "the polymerized molecules frequently react like the simple molecules."

Attempts were made by us in the preparation of iminoacetonitrile. to generate the prussic acid from $\mathrm{KCN}$ and $\mathrm{HCl}$ in the presence of the methyleneaminoacetonitrile, and thus simplify the process. However, as is frequently the case in the conversion of the complex $\mathrm{N}=\mathrm{C}$ to $\mathrm{NH}-\mathrm{CCN}$ by the addition of $\mathrm{HCN}$, the desired result was not attained by this method.

Knoevenage ${ }^{3}$ has shown that aldehyde bisulfite compounds condense with amines with the elimination of water, forming salts of substituted aminomethane sulfonic acids of the general formula $\mathrm{R}_{2} \mathrm{NCH}(\mathrm{R}) \mathrm{SO}_{3} \mathrm{Na}$. These latter substances react readily with potassium cyanide, yielding substitution products of aminoacetonitrile of the general formula, $\mathrm{R}_{2} \mathrm{NCH}(\mathrm{R}) \mathrm{CN}$. It appeared probable that a like result might be attained by adding alkali bisulfite on to the $\mathrm{N}=\mathrm{C}$ complex in methyleneaminioacetonitrile, and then treating the reaction product with $\mathrm{KCN}$. As shown in the experimental part of this article, iminoacetonitrile may be made in this way, but the conditions were not established under which a satisfactory yield could be obtained.

A very comprehensive investigation of iminoacetonitrile has been carried out by Jongkees. ${ }^{4}$ In the course of his work he converted the nitrile to ethyl hydantoino-I-acetate,<smiles>CCOC(=O)CN1CCOC(=O)O1</smiles>

We have been able to improve on his rather complicated process in the preparation of this substance, in that, by treatment of iminoacetonitrile in glacial acetic acid with potassium cyanate, saponification of the ureido.

${ }^{1}$ Loc. cit.

${ }^{2}$ Observation of L. A. Mikeska.

${ }^{3}$ Ber, 37, 4073 (I904).

${ }^{4}$ Rec. trav. chim., 27, 287 (1908). 
derivative thus formed, and then esterification, we pass directly from iminoacetonitrile to the above ethyl hydantoinoacetate with a $45 \%$ yield, and without the isolation of the intermediary products. This process can no doubt be employed in converting other imino acid nitriles. in to the corresponding hydantoino acid esters. The use of glacial acetic acid as a solvent in effecting the urea synthesis was first tried in this laboratory in an investigation of the action of cyanic acid on hydrazo- $i$ butyric acid, $\left(\mathrm{CH}_{3}\right)_{2} \mathrm{CNHNHC}\left(\mathrm{CH}_{3}\right)_{2}$, the results of which work will

\section{$\mathrm{COOH} \mathrm{COOH}$}

be published shortly. Experiments were tried without result to convert iminoacetonitrile to its ureido derivative in the isual way, by the action of potassium cyanate on the hydrochloride of this amine in water solution.

The $\mathrm{H}$ in the $\mathrm{NH}$ group of iminoacetonitrile, in contrast to the imino hydrogen in the corresponding acid, is very reactive, but, especially where an elevated temperature is required to replace this hydrogen, a disturbing factor enters in the case of the nitrile, owing to the ease with which this substance splits off $\mathrm{HCN}$. Although iminodiacetic acid has been known a long time, ${ }^{1}$ no investigator has announced the preparation of corresponding thiohydantoins from this imino acid and mustard oils. As Marckwald, Neumark, and Stelzner ${ }^{2}$ have shown that, in the case of the aliphatic amino acids, it is necessary to salify the carboxyl before the $\mathrm{NH}_{2}$ group will react readily with mustard oils, it appeared probable that salts of iminodiacetic acid, in contrast to the free acid, would condense with mustard oils. We find that by using the acid sodium salt of iminodiacetic acid, it is very easy to prepare thiohydantoins of the general formula<smiles>[R]N1COCN(CC(=O)O)[Si]1</smiles>

which can be readily isolated in the form of their ethyl esters.

Our work on the derivatives of iminodiacetic acid had its origin in the problem of working out a method of passing from imino diacids to hydrazino diacids, corresponding to hydrazinodiacetic acid, $\mathrm{NH}_{2} \mathrm{~N}\left(\mathrm{CH}_{2} \mathrm{COOH}\right)_{2}$. This hydrazine, discovered by Curtius and Hussong, ${ }^{3}$ readily yields with nitrous acid iminodiacetic acid: $\mathrm{NH}_{2} \mathrm{~N}\left(\mathrm{CH}_{2} \mathrm{COOH}\right)_{2}+\mathrm{HNO}_{2}=$ $\mathrm{NH}\left(\mathrm{CH}_{2} \mathrm{COOH}\right)_{2}+\mathrm{N}_{2} \mathrm{O}+\mathrm{H}_{2} \mathrm{O}^{4}$ From the work of Fischer, ${ }^{5}$ Renouf, ${ }^{6}$ and Harries $^{7}$ on the reduction of nitrosamines, it appeared highly

${ }^{1}$ Ann., 122, 257 (1862).

2 Ber., 24, 3278 (1892).

${ }^{3} J$. prakt. Chem., [2] 83, 270 (I9II).

${ }_{4}^{4}$ This Journal, 36, r759 (1914)

'Ann., 190, 146 (1878).

${ }^{6}$ Ibid., 199, 308 (1879).

'Ber, 28, 1223 (1895). 
probable that iminodiacetic acid could be reconverted to hydrazinodiacetic acid by reducing nitrosiminodiacetic acid. Working with methyl nitrosiminodiacetate, $\mathrm{NON}\left(\mathrm{CH}_{2} \mathrm{COOCH}_{3}\right)_{2}$, we have obtained hydrazinodiacetic acid by reduction with sodium amalgam, and experiments are being carried out in this laboratory directed towards the extension of this process to the preparation of other hydrazino diacids. Although this method is of no preparative value in the above case, where it has been applied, it will doubtless prove of value in preparing some of the higher homologs in this series.

\section{Experimental Part.}

Preparation of Iminoacetonitrile from Methyleneaminoacetonitrile and Prussic Acid.-Ioo cc. of absolute prussic acid, containing Io drops of concentrated hydrochloric acid, are poured on $100 \mathrm{~g}$. of methyleneaminoacetonitrile in a thick-walled pressure flask. In about twenty-four hours complete solution is effected, and then later on the iminoacetonitrile begins to crystallize out in an interwoven mass of long prisms. At the end of forty-eight hours the excess of prussic acid is recovered by distilling it off below $50^{\circ}$, and finally a further small amount is removed from the nitrile by allowing it to stand in vacuo. The compound is then purified by recrystallization from acetic ether, and finally from benzene. Petrolic ether is an excellent solvent for purification, where small amounts of the nitrile are to be identified, as even from smears it can be regained colorless in long, hair-like needles by the use of this solvent. Prepared in the above way, iminoacetonitrile melts sharply and undecomposed at $75^{\circ}$, as determined by Eschweiler. In working with this substance the fact should be borne in mind that on prolonged heating in solvents, it evolves prussic acid. As a further identification of the preparation obtained by the action of prussic acid on methyleneaminoacetonitrile, it was converted according to the directions of Eschweiler into the corresponding acid, and into the characteristic hydrochloride of the methyl ester described by Jongkees. The following analysis and molecular weight determinations were made on the nitrile prepared by the new process:

Calc. for $\mathrm{C}_{4} \mathrm{H}_{5} \mathrm{~N}_{3}: \mathrm{C}, 50.53 ; \mathrm{H}, 5.26 ; \mathrm{N}, 44.2 \mathrm{I}$; found: $\mathrm{C}, 50.67 ; \mathrm{H}, 5.36 ; \mathrm{N}, 44.39$.

Three molecular weight determinations by the freezing point method with acetic acid as the solvent gave 105, 107 , and 106. Calc. for $\mathrm{C}_{4} \mathrm{H}_{5} \mathrm{~N}_{3}: 95$.

The following modifications of making iminoacetonitrile as described above were tried in the hope of obviating the use of free prussic acid: One gram of methyleneaminoacetonitrile and I $\mathrm{g}$. of $\mathrm{KCN}$ were dissolved in the least amount of water at $60^{\circ}$, and then I mol of $\mathrm{HCl}$ allowed to drop into the solution. Not a trace of iminoacetonitrile could be detected, but considerable unchanged methylene compound was recovered. In a second experiment $\mathrm{I} g$. of methyleneaminoacetonitrile was stirred into a solution of sodium bisulfite, prepared from $0.8 \mathrm{~g}$. of $\mathrm{Na}_{2} \mathrm{CO}_{3}$ ) and $2.7 \mathrm{~g}$. 
of water in the usual way. The methylene compound dissolved readily with an elevation of temperature of $15^{\circ}$, so that there is little doubt that in this process the bisulfite adds onto the $\mathrm{N}=\mathrm{C}$ complex. The new substance can be precipitated along with inorganic admixtures by the addition of alcohol, but, because of its ready solubility in water and its insolubility in organic solvents, a method of purification was not found. However, when the reaction mixture of bisulfite and the methylene compound was treated with one $m o l$ of $\mathrm{KCN}$ in water solution at $60^{\circ}$, the solu:tion concentrated to a pasty consistency in vacuo on a water bath, and the residue extracted with petrolic ether, a considerable amount of iminoacetonitrile was obtained.

Salts of Iminoacetonitrile.-The only salt of iminoacetonitrile described in the literature is the hydrochloride, which, according to Eschweiler, precipitates on leading hydrochloric acid gas into an ether solution of the nitrile. $^{1}$ We found that a convenient way to prepare this salt is to dissolve the nitrile in $20 \% \mathrm{CH}_{3} \mathrm{OH}-\mathrm{HCl}$ by slightly warming. In a few minutes after solution, the nitrile separates as the hydrochloride in characteristic long prisms.

A more stable salt than the hydrochloride is the nitrate, which may be prepared as follows: I $\mathrm{g}$. of the nitrile is dissolved in $4 \mathrm{cc}$. of concentrated nitric acid, and the precipitation of the salt effected by the addition of $4 \mathrm{cc}$. of absolute alcohol. For purification the nitrate is dissolved in boiling alcohol, and then precipitated by the addition of ether. It.crystallizes from alcohol in very long slender needles, which melt at $134-135^{\circ}$, apparently undecomposed, but in a few seconds the liquid blackens with gas evolution. The nitrate, like the hydrochloride, hydrolizes in water solution, from which, on shaking out with ether, the free iminoacetonitrile may be regained. 35.65 .

Calc. for $\mathrm{C}_{4} \mathrm{H}_{6} \mathrm{O}_{3} \mathrm{~N}_{4}: \mathrm{C}, 30.38 ; \mathrm{H}, 3.80 ; \mathrm{N}, 35.44$; found: $\mathrm{C}, 30.70 ; \mathrm{H}, 3.98 ; \mathrm{N}$,

Nitrosiminoacetonitrile, $\mathrm{NON}\left(\mathrm{CH}_{2} \mathrm{CN}\right)_{2}$.- If to $\mathrm{I}$ g. of iminoacetonitrile in 10.5 cc. of $\mathrm{N} \mathrm{H}_{2} \mathrm{SO}_{4}$ a concentrated solution of $0.75 \mathrm{~g}$. of $\mathrm{NaNO}_{2}$ be added, there separates immediately a light yellow oil, which on cooling and stirring solidifies. The nitrosamine thus obtained gives the Liebermann reaction. It is more difficultly soluble than the parent substance in all solvents. For analysis it was purified by precipitation from an acetic ether solution by the addition of petrolic ether, as well as by recrystallization from benzene. It crystallizes in the form of slender prisms of a faint yellow color, melting undecomposed at $38^{\circ}$. Snessarew gives $5 \mathrm{I}-52^{\circ}$. as the melting point of nitroso- $\alpha$-iminoisobutyronitrile, ${ }^{2}$ while Passavant describes nitroso- $\alpha$-iminopropionitrile as an oil. ${ }^{3}$ The melting point of

${ }^{1} A n n ., 278,23$ I (1894).

2 J. prakt. Chem., [2] 89, 364 (I914).

${ }^{3}$ Ann., 200, I3I (I880). 
iminopropionitrile lies between that of the corresponding iminonitriles of Eschweiler and Snessarew, so that in all probability the nitroso derivative of iminopropionitrile can be obtained as a solid like the above homologs. Our attempts to reduce nitrosiminoacetonitrile with sodium amalgam to hydrazinodiacetonitrile, and isolate the latter in the form of the corresponding difficultly soluble hydrazinodiacetic acid have thus far failed, because the nitroso compound is decomposed in the alkaline solution. However, further attempts will be made to establish conditions under which a reduction can be effected. Despite the fact that this nitrosamine appears perfectly stable, none of the analyses, which were made on three different preparations, agreed closely with the calculated percentages, and it may be that the melting point given above will be found too low, when carried out on a perfectly pure sample.

Calc. for $\mathrm{C}_{4} \mathrm{H}_{4} \mathrm{ON}_{4}$ : C, $38.7 \mathrm{I} ; \mathrm{H}, 3.23 ; \mathrm{N}, 45.16$; found: $\mathrm{C}, 39.31 ; 39.19,39.19 ; \mathrm{H}$, $3.32,3.39,3.31 ; \mathrm{N}, 44.88,44.45,44.50$.

Benzoyliminoacetonitrile, $\mathrm{C}_{6} \mathrm{H}_{5} \mathrm{CON}\left(\mathrm{CH}_{2} \mathrm{CN}\right)_{2}$. - Jongkees obtained acetyliminoacetonitrile as a viscous oil, boiling at $227^{\circ}$ under $16 \mathrm{~mm}$. pressure, but was unable to make the substance crystallize. We find that the benzoyl derivative in contrast to the acetyl compound is a beautifully crystallizing substance, which can be readily prepared from iminoacetonitrile in benzene solution by heating it with one mol of benzoyl chloride. The benzoyl derivative thus prepared is readily soluble in alcohol, chloroform, acetic ether, and water, and difficultly soluble in ether and benzene. Recrystallized from alcohol, it is obtained in diamond shaped prisms, made up apparently of laminated plates, melting undecomposed at $131-132^{\circ}$.

Calc. for $\mathrm{C}_{11} \mathrm{H}_{8} \mathrm{ON}_{3}$ : C, 66.33; H, 4.52; N, $21.1 \mathrm{I} ;$ found: $\mathrm{C}, 66.08 ; \mathrm{H}, 4.68 ; \mathrm{N}$, 25.25 .

Ethyl Hydantoino-I-acetate, $\mathrm{CO}-\mathrm{N}-\mathrm{CH}_{2} \mathrm{COOC}_{2} \mathrm{H}_{6}-2$ g. of finely pow-<smiles>[NH]C(=O)[O-]</smiles>

dered potassium cyanate are stirred into a solution of $2 \mathrm{~g}$. of iminoacetonitrile in $20 \mathrm{cc}$. of glacial acetic acid, whereupon reaction proceeds with a temperature elevation of about $16^{\circ}$. After several hours' standing, the mixture is evaporated to dryness in vacuo, the residue saponified by boiling with $20 \mathrm{cc}$. of concentrated hydrochloric acid, the solution again evaporated to dryness, and finally the hydantoino acetic acid esterified by boiling for two hours with $50 \mathrm{cc}$. of $5 \% \mathrm{C}_{2} \mathrm{H}_{5} \mathrm{OH}-\mathrm{HCl}$. After driving off the alcohol, the hydrochloride of the ester is dissolved in a little water, the solution made just alkaline, with ammonia, and then the ester extracted with chloroform. The substance, purified by recrystallization from alcohol and benzene, corresponded in its properties with the prepara 
tion obtained by Jongkees with carboxymethyliminoacetonitrile, $\mathrm{CH}_{3} \mathrm{OCON}\left(\mathrm{CH}_{3} \mathrm{CN}\right)_{2}$ as the starting substance. ${ }^{1}$ Our yield of hydantoino ester by the above process was about $44 \%$ of the theoretical. The same substance was obtained by the action of sodium ethoxide on methyl ureidodiacetate in ethyl alcohol solution. ${ }^{2}$ As a further confirmation of the constitution of the ethyl hydantoinoacetate prepared by us, a nitrogen determination was made.

Calc. for $\mathrm{C}_{7} \mathrm{H}_{10} \mathrm{O}_{4} \mathrm{~N}_{2}: \mathrm{N}, 15.05$; found: $\mathrm{N}, 15.35$.

Ethyl 3-Phenyl-2-thiohydantoino-I-acetate,

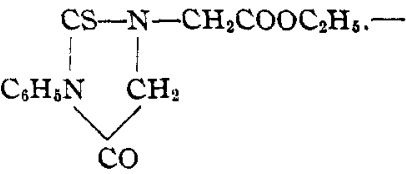

For the preparation of this hydantoin, $2 \mathrm{~g}$. of iminoacetonitrile, dissolved in 2 mols of $N \mathrm{NaOH}$, are allowed to stand 48 hours, and then the solution is boiled until there is no further escape of ammonia. One-half of the alkali is now neutralized with $\mathrm{HCl}$, the solution evaporated to a small volume, $2.8 \mathrm{~g}$. of phenyl mustard oil in $20 \mathrm{cc}$. of alcohol added, and the mixture boiled under a return condenser for 6 hours. The solution is next evaporated to dryness, and the residue containing the hydantoin esterified by boiling it with $50 \mathrm{cc}$. of $5 \% \mathrm{C}_{2} \mathrm{H}_{5} \mathrm{OH}-\mathrm{HCl}$ for 2 hours, and then proceeding just as in the preparation of the above ethyl hydantoinoacetate. The yield obtained on the thiohydantoin was about $72 \%$ of the theoretical. It crystallizes from alcohol in long, slender prisms with dome-shaped end faces, which melt undecomposed at $\mathrm{r} 34^{\circ}$. The compound is difficultly soluble in water and readily soluble in the common organic solvents, petrolic ether excepted.

Calc. for $\mathrm{C}_{13} \mathrm{H}_{14} \mathrm{O}_{3} \mathrm{~N}_{2} \mathrm{~S}: \mathrm{C}, 56.12 ; \mathrm{H}, 5.04 ; \mathrm{N},{ }_{10.07} ; \mathrm{S}, \mathrm{II} .5 \mathrm{I}$; found: $\mathrm{C}, 56.27 ; \mathrm{H}$, $5.25 ; \mathrm{N}$, I0.28; S, II.49.

Ethyl-3-Methyl-2-thiohydantoino-I-acetate. - This hydantoin, prepared by the use of methyl mustard oil similarly to the phenyl compound, can be recrystallized from petrolic ether in the form of slender needles, which melt undecomposed at $62^{\circ}$. The methyl hydantoin is readily soluble in all the common solvents.

Calc. for $\mathrm{C}_{8} \mathrm{H}_{12} \mathrm{O}_{3} \mathrm{~N}_{2} \mathrm{~S}: \mathrm{N}, 12.92$; found: $\mathrm{N}, 13.06$.

Preparation of Hydrazinodiacetic Acid from Methyl Nitrosoiminodiacetate. $-0.5 \mathrm{~g}$. of $\mathrm{HCl}-\mathrm{NH}\left(\mathrm{CH}_{2} \mathrm{COOCH}_{3}\right)_{2}$, prepared according to the method of Jongkees ${ }^{1}$ were dissolved in Io cc. of water, and to this solution r.75 g. of $\mathrm{NaNO}_{2}$ in $2 \mathrm{cc}$. of water were added. $3.5 \mathrm{~g}$. of methyl nitrosiminodiacetate separated as a yellow oil, heavier than water. No analysis was made on this preparation, as it is described in an article by Curtius,

1 Loc. cit.

2 See the following article. 
Darapsky and Mueller. ${ }^{1}$ The $3.5 \mathrm{~g}$. of crude nitroso compound, obtained in the above experiment, were dissolved in $29 \mathrm{cc}$. of $50 \%$ alcohol, and reduced at $10^{\circ}$ by introducing $5 \circ \mathrm{g}$. of $5^{\circ}$ sodium amalgam in small portions, with constant shaking. After the amalgam had become exhausted, ro cc. of water were added and the solution, poured off from the mercury, was boiled a few minutes. On making the solution just acid with $\mathrm{HCl}, 0.6 \mathrm{~g}$. of almost pure hydrazinodiacetic acid crystallized out. Reduction of the aqueous solution, from which the $3.5 \mathrm{~g}$. of nitroso compound separated, with $25 \mathrm{~g}$. of amalgam yielded an additional $0.3 \mathrm{~g}$. of the hydrazino acid. The substance proved identical in every respect with a sample of hydrazinodiacetic acid, made from hydrazine hydrate and monochloroacetic acid. ${ }^{2}$ The following analysis was made on the sample obtained in the above reduction and purified by recrystallization from water:

$$
\text { Calc. for } \mathrm{C}_{4} \mathrm{H}_{8} \mathrm{O}_{4} \mathrm{~N}_{2}: \mathrm{N}, 18.92 \text {; found: } \mathrm{N}, 18.88 \text {. }
$$

Austrin, Texas.

[CONTRIBUTION FROM THE CHEMICAL LABORATORY OF THE UNIVERSTTY OF TEXAS.]

\section{THE NITROSO DERIVATIVES OF SEMICARBAZINODIACETIC ACID ESTERS.}

BY J. R. BAILEY AND D. F. SNYDER.

Received February 8, 1915.

Introduction.

In studying the relation between the derivatives of hydrazinodiacetic acid and those of iminodiacetic acid, we had occasion to repeat the work of Bailey and Read ${ }^{3}$ on the action of nitrous acid on methyl semicarbazinodiacetate. They showed that in this reaction methyl iminodiacetate is formed, but did not succeed in isolating the intermediary nitroso compound, $\mathrm{NH}_{2} \mathrm{CON}(\mathrm{NO}) \mathrm{N}\left(\mathrm{CH}_{2} \mathrm{COOCH}_{3}\right)_{2}$. We find that this primary reaction product can be isolated and analyzed, but after a few hours standing undergoes spontaneous decomposition as follows:

$\mathrm{NH}_{2} \mathrm{CON}(\mathrm{NO}) \mathrm{N}\left(\mathrm{CH}_{2} \mathrm{COOCH}\right)_{2}=\mathrm{NH}_{2} \mathrm{CON}\left(\mathrm{CH}_{2} \mathrm{COOCH}_{3}\right)_{2}+\mathrm{N}_{2} \mathrm{O}$

The constitution of this new substance as methyl ureidodiacetate was es tablished by its synthesis from the hydrochloride of methyl iminodiacetate ${ }^{4}$ and potassium cyanate, as well as by its conversion to esters of hydantoino-I-acetic acid. ${ }^{5}$ In the sodium alcoholate condensation of methyl ureidodiacetate to a hydantoin, ${ }^{6}$ it was found that the methyl

1 Ber., 4I, 356 (1908).

2 J. prakt. Chem., [2] 83, 27 I (I9II); ThIS Journal, 36, I747 (I914).

${ }_{3}$ This Journal, 36, 1747 (1914).

${ }^{4}$ Rec. trav. chim., 27, 287 (1908).

${ }^{5}$ See foregoing article of Bailey and Snyder.

${ }^{6}$ Cf. Am. Chem. J., 28, 386 (I g02). 